\title{
Pengaruh Model Pembelajaran Kooperatif Tipe Group Investigation terhadap Hasil Belajar Geografi
}

\author{
Achmad Taher ${ }^{1}$, Sugeng Utaya ${ }^{1}$, Syamsul Bachri ${ }^{1}$ \\ ${ }^{1}$ Pendidikan Geografi-Universitas Negeri Malang
}

\begin{tabular}{|c|c|}
\hline INFO ARTIKEL & ABSTRAK \\
\hline Riwayat Artikel: & $\begin{array}{l}\text { Abstract: This study aims to determine the differences in student geography learning } \\
\text { outcomes taught with the group investigation model and those taught by conventional }\end{array}$ \\
\hline Diterima: 17-01-2019 & methods (discussion). This type of research is a quasi-experimental (quasi experimental). \\
\hline Disetujui: 17-04-2019 & The study design used a pretest - posttest non-equivalent control group design. The data \\
\hline $\begin{array}{l}\text { cooperative learning; } \\
\text { group investigation; } \\
\text { geography learning outcomes; } \\
\text { pembelajaran kooperatif; } \\
\text { group investigation; } \\
\text { hasil helaiar gooorafi }\end{array}$ & $\begin{array}{l}\text { analysis used is the independent sample t-test value of the gain score with the help of the } \\
\text { SPSS } 16.0 \text { for Windows application. The results showed that there were significant } \\
\text { differences in geographic learning outcomes between the experimental class and the } \\
\text { control class. The value of geography learning outcomes of students taught with group } \\
\text { investigation models is better than the geography learning outcomes of students who are } \\
\text { taught using conventional methods (discussion). This is because students who conduct } \\
\text { investigations can understand geography learning material on the topic of coastal abrasion } \\
\text { better than students who study conventionally. }\end{array}$ \\
\hline
\end{tabular}

\begin{abstract}
Abstrak: Penelitian ini bertujuan untuk mengetahui perbedaan hasil belajar geografi siswa yang diajar dengan model group investigation dan yang diajar dengan metode konvensional (diskusi). Jenis penelitian ini merupakan eksperimen semu (quasi experimental). Rancangan penelitian menggunakan pretest-posttest non-equivalent control group desain. Analisis data yang digunakan adalah uji independent sample t-test nilai dari gain score dengan bantuan aplikasi SPSS 16.0 for windows. Hasil penelitian menunjukkan adanya perbedaan hasil belajar geografi yang signifikan antara kelas eksperimen dan kelas kontrol. Nilai hasil belajar geografi siswa yang diajar dengan model group investigation lebih baik dibanding hasil belajar geografi siswa yang diajar dengan metode konvensional (diskusi). Hal ini disebabkan siswa yang melakukan investigasi dapat memahami materi pembelajaran geografi topik abrasi pantai lebih baik dibanding siswa yang belajar secara konvensional.
\end{abstract}

\author{
Alamat Korespondensi: \\ Achmad Taher \\ Pendidikan Geografi \\ Universitas Negeri Malang \\ Jalan Semarang 5 Malang \\ E-mail: achmadtaher93@gmail.com
}

Permasalahan yang kerap ditemukan dalam pendidikan formal adalah mengenai hasil belajar Geografi siswa masih rendah. Permasalahan hasil belajar Geografi disebabkan oleh faktor-faktor dari sistem yang diterapkan sekolah atau cara pembelajaran dan faktor lainya. Rendahnya hasil belajar Geografi harus segera diatasi. Menyelesaikan permalahan hasil belajar seyongyanya harus dilakukan oleh guru dan sekolah. Oleh karena itu, seorang guru hendaknya menjadikan pembelajaran Geografi lebih menarik. Sebagai mata pelajaran formal pembelajaran Geografi tidak hanya dibatasi di dalam kelas saja, melainkan membawa siswa berintekasi dengan realitas kehidupan sehingga pembelajaran menarik (Khafid, 2010). Pembelajaran geografi harus dikaitkan dengan kehidupan siswa atau berbasis pembelajaran kontekstual dan tidak bersumber pada buku teks saja, agar pengetahuan siswa dapat berkembang dan merangsang imajinasi mereka dengan pembelajaran berbasis lingkungan hidup.

SMA Negeri 1 Arjasa merupakan sekolah yang berada di Kepulauan Kangean Kabupaten Sumenep masih ditemukan rendahnya hasil belajar Geografi. Hasil pengamatan di SMA Negeri 1 Arjasa membuktikan bahwa pembelajaran yang dalam kelas menggunakan metode konvensional (ceramah) guru menyampaikan materi dan siswa hanya sebagai pendengar. Faktor yang menyebabkan timbulnya permasalahan dalam pembelajaran, seperti strategi pembelajaran yang diterapkan di sekolah kurang kurang inovatif (Sudarman, dkk., 2018). Hasil wawancara dengan guru yang dilakukan di SMA Negeri 1 Arjasa menunjukkan bahwa masih terdapat siswa kurang aktif bertanya, kurang dalam menanggapi pelajaran, kurang dalam mengemukakan pendapat sehingga aktivitas belajar kurang optimal dan hasil belajar geografi rendah. Untuk mendapatkan hasil belajar siswa yang baik maka harus mengupayakan aktivitas belajar dinamis (Darsono, 2000). 
Aktivitas belajar siswa dinilai sangat penting karena dapat memengaruhi prestasi belajar atau hasil belajar mereka. Menurut Astuti \& Haryono, (2017) kondisi pembelajaran yang menarik akan menambah minat siswa mengikuti proses pembelajaran, salah satu upaya perbaikan untuk menjadikan pembelajaran disukai siswa adalah dengan menerapkan model pembelajaran yang memberikan ruang terhadap aktivitas belajar siswa, salah satunya dengan diberikan model pembelajaran kooperatif Group Investigation (GI).

Hasil belajar Geografi siwa merupakan aspek yang harus dievaluasi sehingga dapat diperbaiki. Penilaian hasil belajar hendaknya berpatokan pada tujuan-tujuan kurikuler dan tujuan intruksionalnya (Sudjana, 2014). Hasil belajar Geografi siswa yang diukur pada penelitian ini adalah pada kategori high older thinking, yaitu (a) menganalisis karakteristik perairan laut di Pulau Kangean; (b) menguraikan dampak akibat dinamika perairan laut di Pulau Kangean; (c) menganalisis kondisi pesisir di Pulau Kangean; (d) merencanakan tindakan konservasi daerah pesisir di Pulau Kengean. Acuan dalam penyusunan soal untuk memperbaiki hasil belajar Geografi siswa yaitu menggunakan kriteria Taksonomi Bloom ranah kognitif disusun dari soal-soal yang paling mudah hingga soal-soal yang paling sulit. Hal ini bertujuan utuk mengetahui ranah kognitif yang telah dicapai siswa, serta bertujuan untuk menyusun strategi meningkatkan kemampuan siswa (Sudewi, dkk., 2014).

Paradigma dalam pembelajaran Geografi harus diganti dengan menjadikan pembelajaran berpusat pada siswa. Pembelajaran seharusnya tidak berfokus pada hasil belajar semata, melainkan harus memikirkan proses belajar siswa dan pengelolaan pembelajaran guru (Khafid, 2010). Guru Geografi harus terampil dalam membelajarkan berbasis spasial berdasarkan materi atau topik yang akan dibahas, siswa harus diajarkan cara penyajian data dalam bentuk tabel, diagram, peta dan lainnya. Pembelajaran Geografi hendaknya menggunakan pendekatan keruangan, guru mengarahkan siswa untuk belajar dengan cara mengamati kondisi keruangan di sekitar mereka. Berpikir mengenai keruangan merupakan cara untuk mengaktifkan menalar dalam mempelajari fenomena yang terjadi, tentunya harus disertai bekal ilmu dan pengetahuan sehingga siswa aktif dalam pembelajaran.

Upaya untuk mengoptimalkan proses pembelajaran yang melibatkan siswa aktif adalah dengan menggunakan model pembelajaran kooperatif group investigation (GI). Cooperative learning memberikan kesempatan siswa untuk terampil berkomunikasi dan membentuk aktivitas interaktif dalam proses belajar (Siskandar, 2009). Group investigation memberikan kesempatan siswa dalam bepartisipasi dan aktif untuk mencari materi yang akan dipelajari, misalnya dari buku atau melalui internet (Azizah \& Nasrudin, 2013). Model pembelajaran group investigation memudahkan guru dalam menghubungkan materi pembelajaran dengan fenomena dilingkungan siswa sehingga siswa mampu membuat keterkaitan materi pembelajaran dengan fenomena di lingkungannya (Sumarmi, 2012). Proses pembelajaran menjadi lebih bervariasi dengan adanya penerapan model pembelajaran kooperatif. Strategi belajar dengan mengolaborasikan sejumlah siswa sebagai anggota kelompok heterogen dengan kemampuan kognitif yang berbeda merupakan pembelajaran kooperatif (Laila, dkk., 2016).

Model group investigation melibatkan peran aktif siswa dan guru. Pelaksanaan investigasi melibatkan siswa belajar secara berkelompok dengan didampingi oleh guru (Slavin, 2010). Model group investigation digunakan untuk menjadi arahan dalam aktivitas belajar Geografi dengan menerapkan sintak-sintak pembelajaran GI agar aktivitas belajar terarah dengan baik. Siswa dituntut aktif dalam pelajaran sehingga mereka mendapatakan pengalaman dan pengetahuan. Aktivitas group investigation mulai dari kegiatan membentuk kelompok dan menentukan topik, membuat rencana kelompok, pelaksanaan investigasi, Menganalisis hasil dan menyiapkan laporan hingga menyajikan laporan (Sumarmi, 2012). Belajar secara berkelompok dapat meningkatkan kerja sama antara siswa sehingga diharapkan pemebelajaran akan berhasil (Rahayu, dkk., 2017). Dengan pengalaman dan pengetahuan yang mereka miliki, siswa mampu untuk menjawab tes yang diberikan sehingga hasil belajar siswa akan meningkat.

Kedepan pembelajaran Geografi harus dikaitkan dengan kehidupan siswa atau berbasis pembelajaran kontekstual dan tidak bersumber pada buku teks saja. Pembelajaran kontekstual yang berkaitan secara langsung dengan kehidupan mereka akan mampu diserap dengan baik oleh siswa. Siswa memperoleh pengetahuan dari proses menyelesaikan masalah sehingga diharapkan siswa dapat menyelesaikan permasalahan-permasalahan yang ada di masyarakat (Sumarmi, 2012). Belajar dengan melibatkan siswa secara langsung menjadi lebih mudah siswa memahami materi yang dibelajarkan (Nuraeni, dkk., 2017). Dari uraian permasalahan hasil belajar siswa dapat disimpulkan bahwa seorang guru harus mampu mengaitkan pembelajaran Geografi dengan lingkungan di sekitar sehingga siswa bisa belajar dari kehidupan mereka. Aktivitas pembelajaran akan semakin bermakna apabila seorang guru mampu mengaitkan pembelajaran Geografi dengan lingkungan di sekitar sehingga siswa bisa belajar dari kehidupan mereka.

Salah satu materi abrasi atau erosi pantai terdapat pada kompetensi dasar 3.5 menganalisis dinamika litosfer dan dampaknya terhadap kehidupan yang dapat dipelajari secara kontekstual. Abrasi merupakan permasalahan perubahan topografi pantai yang dapat mengancam kondisi pesisir, merusak ekosistem yang ada, dan bisa menimbulkan bencana di daerah pesisir yang berdampak pada bangunan dan lingkungan sekitar (Hakim, dkk., 2012). Permasalahan dinamika litosfer yang dapat dijadikan topik investigasi adalah abrasi pantai di Pulau Kengean, informasi yang perlu diperoleh siswa, yaitu penyebab abrasi, dampak abrasi, dan cara pencegahannya merupakan proses tenaga eksogen dan pengaruhnya terhadap kehidupan. 


\section{METODE}

Penelitian ini menggunakan rancangan penelitian eksperimen semu (quasi exsperiment) dan menggunakan rancangan pretest-posttest non-equivalent control group desain. Peneliti memilih dua kelas, yakni kelas X IPS 1 sebagai kelas eksperimen (model group investigation) dan kelas X IPS 2 sebagai kelas kontrol (model konvensional). Teknik pengumpulan data penelitian memakai tes kemampuan hasil belajar Geografi pada ranah kognitif. Bentuk soal adalah essay terdiri dari lima butir soal yang disesuaikan dengan indikator high order thinking hasil belajar yakni siswa mampu menganalisis (C4), siswa dapat memeriksa (C4), siswa dapat merencanakan (C6), siswa dapat menguraikan (C4), siswa dapat menemukan (C4). Uji prasyarat pada penelitian ini terdiri dari uji normalitas, homogenitas, dan uji hipotesis. Hipotesis penelitian diperoleh dari hasil analisis menggunakan analisis statistik uji independent sample t-test dari nilai gain score hasil belajar.

\section{HASIL}

Uji asumsi klasik dilakukan sebagai syarat statistik parametrik yang harus terpenuhi dalam melakukan analisis, terdiri dari uji homogenitas dan uji normalitas sebelum uji independent sample t-test. Setelah data berdistribusi normal dan bersifat homogen kemudian dilanjutkan uji independent sample t-test dari nilai gain score. Penelitian bertujuan untuk mengetahui perbedaan hasil belajar antara siswa yang dibelajarkan dengan group investigation (GI) dan siswa yang dibelajarkan dengam metode konvensional (diskusi) terhadap hasil belajar Geografi. Pada tabel 1 disajikan analisis data klasikal dan analisis independent sample t-test dari nilai gain score hasil belajar Geografi siswa pada kelas eksperimen dan kontrol.

Tabel 1. Data Klasikal Posttest Hasil Belajar Geografi

\begin{tabular}{lcccc}
\hline \multicolumn{1}{c}{ Kelas } & N & Skor Terendah & Skor Tertinggi & Rata-Rata \\
\hline Eksperimen & 22 & 65 & 93 & 79,8 \\
Kontrol & 20 & 50 & 80 & 61,55 \\
\hline
\end{tabular}

\section{Sumber: Hasil Olah Data Penelitian 2019}

Berdasarkan data pada tabel 1, nilai posttest hasil belajar siswa kelas eksperimen dengan jumlah 22 siswa memperoleh skor terendah 65, skor tertinggi 91 dengan perolehan nilai rata-rata 79. Nilai posttest hasil belajar Geografi siswa kelas kontrol berjumlah 20 siswa memperoleh skor terendah 50, skor tertinggi 80, dan dengan perolehan nilai rata-rata 65 . Kedua kelas subjek penelitian mengalami peningkatan hasil belajar posttest. Namun, pada kelas eksperimen yang diajarkan dengan group investigation mengalami peningkatan hasil belajar Geografi siswa dengan nilai rata-rata lebih tinggi daripada kelas kontrol.

Tabel 2. Data Gain Score Hasil Belajar Geografi

\begin{tabular}{ccc}
\hline \multirow{2}{*}{ Statistik Deskriptif } & Kelas Eksperimen & Kelas Kontrol \\
\cline { 2 - 3 } & Hasil Belajar & Hasil Belajar \\
\hline Jumlah Sampel (N) & 22 & 20 \\
Nilai Minimum & 11 & 0 \\
Nilai Maksimum & 32 & 20 \\
Rat-Rata (Mean) & 20,77 & 5,55 \\
Standar Deviasi & 6,77 & 6,04 \\
\hline
\end{tabular}

\section{Sumber: Hasil Olah Data Penelitian 2019}

Data gain score pada tabel 2 menunjukkan bahwa nilai rata-rata hasil belajar Geografi siswa kelas eksperimen yaitu 20,77 dengan nilai minimum yaitu 11 dan nilai maksimum yaitu 32 dan standar deviasi 6,77. Sementara itu, nilai rata-rata dari gain score hasil belajar geografi siswa kelas kontrol yaitu 5,55 dengan nilai minimum yaitu 0 dan nilai maksimum yaitu 20 dan standar deviasi 6,04. Perbedaan hasil perolehan siswa disebabkan adanya perbedaan perlakuan di kedua kelas. Kelas eksperimen dibelajarkan dengan model pembelajaran kooperatif tipe group investigation, sedangkan pada kelas kontrol diberlakukan metode konvensional (diskusi).

Tabel 3. Independent Sample T-Test Gain Score Hasil Belajar

\begin{tabular}{ccccc}
\hline & T hitung & $\begin{array}{c}\text { T tebel } \\
(\mathbf{d f}=\mathbf{4 0})\end{array}$ & Signifikansi & Keterangan \\
\hline Gain Score & 7,651 & 2,021 & 0,000 & Signifikan \\
\hline
\end{tabular}

Sumber: Hasil Olah Data Penelitian 2019 
Hasil analisis independent sample t-test gain score hasil belajar Geografi siswa pada tabel 3 menunjukkan bahwa nilai t hitung 7,651 > t tabel 2,021 dan nilai signifikasi 0,000 sehingga dapat disimpulkan terlihat perbedaan gain score hasil belajar geografi posttest kedua kelas. Perbedaan hasil perolehan siswa disebabkan adanya perbedaan perlakuan di kedua kelas. Pada kelas eksperimen diberlajarkan dengan model pembelajaran kooperatif tipe group investigation, pada kelas kontrol diberlajarkan dengan metode konvensional (diskusi). Pembelajaran berbasis investigasi ternyata efektif sebagai upaya untuk memperbaiki atau meningkatkan hasil belajar Geografi siswa.

\section{PEMBAHASAN}

Berdasarkan hasil analisis diketahui bahwa skor hasil belajar Geografi kelas eksperimen dengan model group investigation lebih baik dibanding kelas kontrol dengan model konvensional. Model pembelajaran group investigation memiliki karakteristik yang mendukung aktivitas belajar Geografi. Untuk mendapatkan hasil belajar siswa yang baik maka harus mengupayakan aktivitas belajar dinamis (Darsono, 2000). Model pembelajaran group investigation melibatkan siswa aktif dan melatih berpikir tingkat tinggi serta menumbuhkan kemampuan berpikir mandiri didalam tahapan atau proses pembelajaran (Slavin, 2010). Kecakapan berpikir siswa meningkat ketika belajar dengan model kelompok investigasi (Azizah \& Nasrudin, 2013). Siswa melakukan investigasi untuk pengumpulan data mampu meningkatkan kemampuan kognitif mereka.

Pembelajaran model GI terbukti mampu meningkatkan hasil belajar Geografi siswa. Penelitian relevan tentang pembelajaran berbasis investigasi membuktikan bahwa pembelajaran ini mampu meningkatkan hasil belajar siswa. Penelitian oleh Azizah \& Nasrudin, (2013) tentang kecakapan berpikir siswa. Penelitian oleh (Astuti \& Haryono, 2017) tentang hasil belajar siswa kelas X IPS. Penelitian oleh (Laila, dkk., 2016) tentang motivasi belajar IPS siswa. Penelitian oleh Murtiningsih \& Komalasari, (2017) tentang meningkatkan kecakapan siswa. Penelitian oleh Khafid, (2010) tentang hasil belajar Geografi. Penelitian relevan merupakan landasan untuk memperkuat hasil temuan penelitian.

Guru Geografi perlu memulai pembelajaran dengan mengaitkan permasalahan kontekstual. Model pembelajaran group investigation memudahkan guru dalam menghubungkan materi pembelajaran dengan fenomena di lingkungan siswa sehingga siswa mampu membuat keterkaitan materi pembelajaran dengan fenomena di lingkungannya (Sumarmi, 2012). Menurut Mite, dkk., (2016) Umumnya manusia dapat belajar melalui pembelajaran visual salah satunya model GI. Hasil belajar IPS siswa dengan pembelajaran berbasis pendekatan kontekstual mengalami peningkatan lebih tinggi secara signifikan dari pada pembelajaran secara konvensional (Afandi, 2015). Pembelajaran kontekstual mampu meningkatkan hasil belajar Biologi siswa (Irwandi, 2013). Pengelolaan proses pembelajaran atau pengelolaan kelas meliputi empat tahapan, yaitu perencanaan tindakan, pengorganisasian siswa, pengarahan, dan pengawasan oleh guru (Nugroho, 2013). Keempat tahapan tersebut dilaksanakan oleh guru bidang studi Geografi untuk diterapkan di kelas dan peneliti bertindak sebagai pengamat aktivitas belajar siswa kelas eksperimen dengan model group investigation dan aktivitas belajar siswa kelas kontrol dengan metode konvensional.

Hasil belajar Geografi siswa meningkat karena adanya aktivitas belajar yang bersifat dinamis. Untuk menigkatkan aktivitas belajar maka siswa harus terlibat langsung ke dalam praktik belajar (Titisari \& Wijayanti, 2014). Aktivitas belajar mahasiswa baik secara individu maupun kelompok sudah lebih baik dan "hidup" hal ini terlihat dari cara mereka menanggapi pertanyaan atau mengomentari paparan diskusi kelompok lain (Masitoh, 2016). Untuk memperoleh hasil belajar IPS yang tinggi setiap siswa berusaha belajar dengan baik (Badu, 2015). Siswa mampu bekerja sama serta aktif belajar untuk keberhasilan kelompok, serta untuk meningkatkan keberhasilan kelompok dan meningkatkan kemampuan dalam mengemukakan pendapat (Hadinata, dkk., 2017). Dalam kegiatan investigasi siswa terlibat dalam penentuan topik serta cara memperoleh data dan siswa terlibat dalam perencanaan dengan begitu siswa memiliki kesempatan belajar dari awal hingga akhir. Siswa memperoleh pengetahuan dari proses menyelesaikan masalah sehingga diharapkan siswa dapat menyelesaikan permasalahan-permasalahan yang ada di masyarakat (Sumarmi, 2012). Hasil belajar siswa diharapkan meningkat dengan bimbingan dari guru (Halek, dkk., 2016). Keterlibatan siswa secara langsung dalam melakukan investigasi masalah menjadi faktor penting yang berpengaruh terhadap hasil belajar Geografi siswa.

Guru sebagai instruktur menugaskan siswa untuk mempersiapkan alat atau bahan yang diperlukan selama proses pengumpulan data. Siswa mempersiapkan daftar wawancara atau daftar pertanyaan yang akan mereka gunakan untuk mengetahui penyebab abrasi pantai di Pulau Kangean. Guru dapat membentuk suatu kelompok heterogen secara khusus, sesuai dengan kemampuan yang dimiliki siswa dalam menunjang aktivitas kelompok (Arsyad, 2014). Selanjutnya, guru memberikan tanggung jawab kepada anggota kelompok investigasi untuk merencanakan tindakan yang akan dilakukan. Guru mengarahkan kepada kelompok agar penyelidikan sesuai dengan tujuan pembelajaran dan topik yang telah ditetapkan, sedangkan pada kelas kontrol, guru menugaskan siswa agar mempersiapkan kegiatan diskusi yang akan dilakukan pada pertemuan kedua.

Siswa melakukan investigasi mulai dari kegiatan mengamati kondisi abrasi pantai di Pulau Kangean. Guru menyarankan agar siswa membuat dugaan tentang penyebab abrasi pantai di daerah tersebut. Pelaksanaan investigasi melibatkan siswa belajar secara berkelompok dengan didampingi oleh guru (Slavin, 2010). Siswa mencari data atau informasi untuk mengetahui jawaban atas dugaan yang telah mereka curigai. Siswa mewawancarai warga yang berada di sekitar lokasi abrasi pantai untuk dimintai keterangan terkait penyebab, dampak, pencegahan terhadap permalahan abrasi pantai. Setelah memperoleh data yang diperlukan siswa berdiskusi dengan kelompok untuk menganalisis secara deduktif dengan mengaitkan informasi dari beberapa sumber termasuk dari hasil wawancara. Kemudian siswa membuat kesimpulan dari dugaan yang telah dianalisis untuk dijadikan laporan investigasi. Kelompok investigasi mempresentasikan hasil laporan lapangan di depan kelas. Sebagian besar siswa terlihat aktif 
bertanya tentang abrasi, menanggapi jawaban yang kurang tepat dengan pengetahuan dari pengalaman mereka saat melakukan investigasi di dalam diskusi yang telah berlangsung. Siswa belajar dari permasalahan yang berkaitan dengan kehidupan mereka, dengan penyelesaian masalah dapat menambah penguasaan wawasan siswa (Marlina, dkk., 2017).

Kompetensi dasar 3.5 menganalisis dinamika litosfer dan dampaknya terhadap kehidupan, topik abrasi pantai merupakan proses tenaga eksogen yang memiliki pengaruh terhadap kehidupan merupakan materi yang dapat diinvestigasi. Group investigations require students to learn independently in groups, teachers as facilitators to facilitate student learning activities (Sharan, 1998). Setelah mengikuti proses pembelajaran dengan menggunakan model group investigation, siswa diharapkan dapat (a) menganalisis karakteristik perairan laut di Pulau Kangean; (b) menguraikan dampak akibat dinamika perairan laut di Pulau Kangean; (c) menganalisis kondisi pesisir di Pulau Kangean; (d) merencanakan tindakan konservasi daerah pesisir di Pulau Kengean. Permasalahan abrasi pantai merupakan permasalahan kontekstual yang diinvestigasi siswa. Kegiatan yang harus dicapai siswa adalah untuk mengetahui penyebab abrasi, dampak abrasi, dan cara pencegahannya yang merupakan proses tenaga eksogen dan pengaruhnya terhadap kehidupan sehingga dapat ditemukan solusi dari sebuah permasalahan di masyarakat.

\section{SIMPULAN}

Berdasarkan hasil penelitian dan pembahasan dapat disimpulkan bahwa model Group Investigation (GI) berpengaruh terhadap hasil belajar Geografi topik abrasi pantai di Pulau Kangean. Pada kelas eksperimen yang diajar dengan model pembelajaran Group Investigation (GI) memperoleh nilai rata-rata gain score yang lebih tinggi dibanding dengan kelas kontrol yang diajar dengan metode diskusi. Hal ini disebabkan siswa yang melakukan investigasi dapat memahami materi pembelajaran Geografi topik abrasi pantai lebih baik dibanding siswa yang belajar secara konvensional.

\section{DAFTAR RUJUKAN}

Afandi, Z. (2015). Pengaruh Strategi Pembelajaran Kontekstual dan Efikasi Diri terhadap Hasil Belajar Sejarah Siswa SMA Kota Kediri. Jurnal Inovasi dan Teknologi Pembelajaran, 1(2), 127-136.

Arsyad, A. (2014). Media Pembelajaran. PT. Raja Grafindo Perseda.

Astuti, Y. T., \& Haryono, A. (2017). Implementasi Metode Brainstorming dalam Model Group Investigation pada Mata Pelajaran Ekonomi untuk Meningkatkan Keaktifan dan Hasil Belajar Siswa Kelas X IPS 3 SMAN 1 Batu. Jurnal Pendidikan Ekonomi, 10(2), 109-117. https://doi.org/10.17977/UM014v10i22017p109

Azizah, U., \& Nasrudin, H. (2013). Pemberdayaan Kecakapan Berpikir Siswa SMA Bertaraf Internasional melalui Pengembangan Perangkat Pembelajaran Materi Redox Reaction Berorientasi "Group Investigation Cooperative." Jurnal Pendidikan dan Pembelajaran, 20(2), 141-151.

Badu, R. (2015). Panjang Tes, Gaya Kognitif, dan Hasil Belajar IPS Peserta Didik Paket B. Jurnal Ilmu Pendidikan, 21(1), 5963.

Darsono. (2000). Belajar dan Pembelajaran. Semarang: IKIP Pres.

Hadinata, L. W., Utaya, S., \& Setyosari, P. (2017). Pengaruh Pembelajaran Student Team Achievement Division dan Diskusi terhadap Hasil Belajar IPA Kelas IV SD. Jurnal Pendidikan: Teori, Penelitian, dan Pengembangan, 2(7), 7.

Hakim, B. A., Suharyanto, \& Hidajat, W. (2012). Efektivitas Penanggulangan Abrasi Menggunakan Bangunan Pantai di Pesisir Kota Semarang. 7.

Halek, E. F., Oetpah, V., \& Seran, Y. (2016). Peningkatan Motivasi dan Hasil Belajar Siswa melalui Model Pembelajaran Inkuiri pada Siswa SMA. Jurnal Pendidikan: Teori, Penelitian, dan Pengembangan, 1(10), 2047-2049.

Irwandi. (2013). Pengaruh Pendekatan Kontekstual terhadap Hasil Belajar Biologi Siswa SMA. Jurnal Ilmu Pendidikan, 19(1), $100-105$.

Khafid, S. (2010). Pembelajaran Kooperatif Model Investigasi Kelompok, Gaya Kognitif, dan Hasil Belajar Geografi. Jurnal Ilmu Pendidikan, 17(1), 73-78.

Laila, N., Hariyono, H., \& Sumarmi. (2016). Meningkatkan Motivasi Belajar Siswa pada Pembelajaran IPS menggunakan Model Pembelajaran Kooperatif Tipe Group Investigation. Jurnal Teori dan Praksis Pembelajaran IPS, 1(2), $123-129$. https://doi.org/10.17977/um022v1i22016p123

Marlina, Utaya, S., \& Yuliati, L. (2017). Pengaruh Authentic Problem Based Learning (aPBL) terhadap Penguasaan Konsep IPA Siswa Kelas IV Sekolah Dasar. Jurnal Pendidikan: Teori, Penelitian, dan Pengembangan, 2(11), 1509-1514.

Masitoh, S. (2016). Peningkatan Aktivitas Belajar dengan Pembelajaran Investigasi Kelompok dalam Kuliah Metode Penelitian PLB II. Jurnal Ilmu Pendidikan, 13(2), 100-107.

Mite, Y., Corebima, A. D., \& Syamsuri, I. (2016). Hubungan Antara Gaya Belajar dengan Hasil Belajar Siswa SMA Katolik Santa Maria Malang Berbasis Skor Terkoreksi Dalam Pembelajaran Biologi melalui Pembelajaran Group Investigation (GI) Tahun Ajaran 2015/2016. Jurnal Pendidikan: Teori, Penelitian, dan Pengembangan, 1(5), 822-827.

Murtiningsih, I., \& Komalasari, K. (2017). Model Group Investigation untuk Meningkatkan Kecakapan Kewarganegaraan. Jurnal Ilmu Pendidikan, 23(1), 83-90.

Nugroho, D. H. (2013). Strategi Pembelajaran Geografi. Yogyakarta: Ombak.

Nuraeni, D., Utaya, S., \& Akbar, S. (2017). Aktivitas Belajar Dalam Pembelajaran Inside-Outside Circle melalui Lesson Study pada Kelas V SD. Jurnal Pendidikan: Teori, Penelitian, dan Pengembangan, 2(9), 1175-1181. 
Rahayu, T. P., Wahjoedi, \& Sudarmiatin. (2017). Peningkatan Aktivitas dan Hasil Belajar Siswa melalui Pembelajaran. Jurnal Pendidikan: Teori, Penelitian, dan Pengembangan, 2(9), 1182-1187.

Sharan, Y. (1998). Enriching the Group and Investigation in the Intercultural Classroom. European Journal of Intercultural Studies, 9(2), 133-140. https://doi.org/10.1080/0952391980090203

Siskandar. (2009). Keefektifan Pendekatan Cooperative Learning Dalam Meningkatkan Aktivitas dan Hasil Belajar Mahasiswa. Jurnal Ilmu Pendidikan, 16(3), 178-185.

Slavin, R. E. (2010). Cooperative Learning. Bandung: Nusa Media.

Sudarman., Handoyo, B., \& Utomo, D. H. (2018). Meningkatkan Hasil Belajar Geografi menggunakan Model Pembelajaran Inkuiri Terbimbing Berbantuan Media Visual. Jurnal Pendidikan: Teori, Penelitian, dan Pengembangan, 3(3), 377381.

Sudewi, N. L., Subagia, I. W., \& Tika, I. N. (2014). Studi Komparasi Penggunaan Model Pembelajaran Problem Based Learning (PBL) dan Kooperatif Tipe Group Investigation (GI) terhadap Hasil Belajar Berdasarkan Taksonomi Bloom. Jurnal Pendidikan IPA Ganesha, 4, 1-9.

Sudjana, N. (2014). Penelitian Hasil Proses Belajar Mengajar. Bandung: PT. Remaja Rosdakarya.

Sumarmi. (2012). Model-Model Pembelajaran Geografi. Malang: Aditya Media Publishing.

Titisari, K. H., \& Wijayanti, A. (2014). Model Pembelajaran Praktikum Akuntansi untuk Meningkatkan Aktivitas Belajar Mahasiswa. Jurnal Pendidikan dan Pembelajaran, 21(2), 194-207. 